Article

\title{
Exploring Perceived Well-Being from Urban Parks: Insights from a Megacity in Latin America
}

\author{
Andrea Parra-Saldívar ${ }^{1}{ }^{(}$, Sebastián Abades ${ }^{2}$, Juan L. Celis-Diez ${ }^{3, *}$ (i) and Stefan Gelcich ${ }^{1,4}$ \\ 1 Departamento de Ecología, Facultad de Ciencias Biológicas, Pontificia Universidad Católica de Chile, \\ Santiago 8331150, Chile; aparra2@uc.cl (A.P.-S.); sgelcich@bio.puc.cl (S.G.) \\ 2 GEMA Center for Genomics, Ecology \& Environment, Facultad de Estudios Interdisciplinarios, \\ Universidad Mayor, Santiago 8580745, Chile; sebastian.abades@umayor.cl \\ 3 Pontificia Universidad Católica de Valparaíso, Escuela de Agronomía, Quillota 2260000, Chile \\ 4 Center of Applied Ecology and Sustainability (CAPES) \& Center for the Socioeconomic Impact of \\ Environmental Policies (CESIEP), Pontificia Universidad Católica de Chile, Santiago 8331150, Chile \\ * Correspondence: juan.celis@pucv.cl; Tel.: +56-9-9228-4640
}

Received: 22 July 2020; Accepted: 19 August 2020; Published: 15 September 2020

\begin{abstract}
Urbanization has impacted biodiversity and ecosystems at a global scale. At the same time, it has been recognized as a driver of the physical and emotional gap between humans and nature. The lack of direct contact with nature can have a negative impact on several aspects of human well-being and change knowledge and attitudes of people towards the environment. However, this phenomenon is still poorly understood in megacities outside developed countries. Here, we explore the relationship between ecological knowledge and self-reported well-being in an important urban park in Santiago, Chile. We conducted semi-structured surveys of park users to explore their beliefs, preferences, ecological knowledge of plants and birds, and self-reported well-being. Citizens associated urban parks mainly with "nature," and particularly with the presence of trees and plants. Trees were recognized as the most relevant elements of urban parks; in turn, birds were ranked as the less relevant. Regarding formal ecological knowledge, respondents correctly identified an average of 2.01 plants and 2.44 birds out of a total of 10 for each taxon, and exotic species were more likely to be recognized. Park users also reported high scores for self-reported well-being. Interestingly, variance of self-reported well-being scores tended to increase at low levels of ecological knowledge of trees, but no significant relationship was detected with knowledge of birds, nor native species. Ecological knowledge of trees was positively related to self-reported well-being. Results suggest that parks can positively contribute to bring people closer to nature in middle-income countries. Improving ecological knowledge can be critical to restore the relationship between humans and nature in megacities.
\end{abstract}

Keywords: urban ecology; ecological knowledge; socioecology; urban birds; urban vegetation; exotic species; biocultural homogenization

\section{Introduction}

"Urban systems remained under studied by ecologist for most part of the last century" [1]. Only a few decades ago, scientists recognized cities as both drivers and responders of global change [2,3]. Today, urbanization is known to impact biodiversity and ecosystem functions worldwide by processes such as biotic homogenization and the progressive loss of native species [4-6]. People living in cities are immersed in a human-modified environment, where nature is often reduced to urban green areas [7] (pp. 719-746). Accordingly, urbanization has been considered as a key driver of the increasing disconnections between humans and nature [8-10]. The lack of direct experiences with nature can 
jeopardize several aspects of human well-being [11-13] such as cognitive restoration, emotional attachment and sense of identity developed with natural places. This is of special concern, since an increasing gap between humans and nature can change the attitudes and emotions of people towards the environment $[10,14-17]$, which in turn fuels this cycle of disconnection $[10,18]$.

Although a relationship between nature and human well-being was initially proposed (e.g., [19]), it was not until the last decade that pathways and mechanisms through which humans engage with nature have been addressed. For instance, Dallimer et al. [11] found that perceived rather than actual species richness was correlated with self-reported well-being. Cameron et al. [20] also reported this relationship between well-being and perceived biodiversity in urban parks and suggested that other factors such as the ability to 'notice beauty in nature' may modulate this relationship. This can also be attributed to the limited ability of people who live in cities to recognize local animal and plant species [21-24]. In fact, a generalized loss of ecological knowledge in urban dwellers has been reported in several wealthy cities [25]. Knowledge has also been negatively related with income within urban areas [26]. This loss of ecological knowledge is worrying, as it has been reported to drive fewer desirable attitudes and emotions towards nature. For instance, Cox and Gaston [27] reported a strong correlation between the number of correctly identified bird species and a self-reported connection to nature. This evidence suggests that ecological knowledge may be a crucial factor underpinning the relationship between human well-being and nature [13]. Exploring how these factors interact can shed light on how to restore the relationship between humans and nature in urban areas.

Most research on extinction of experience, the increasing lack of direct contact between humans and nature [10], and the links between local knowledge and well-being have been conducted in developed countries. This is unfortunate, as the urbanization processes in Latin America have occurred in different sociocultural contexts, and therefore followed different trajectories and paces [28] (pp. 217-234). As two thirds of megacities (i.e., urban agglomerations with population over 10,000,000 or population densities over $2000 \mathrm{hab} / \mathrm{km}^{2}$ ) are emerging in middle- and low-income countries [29], the focus on developed countries could eventually present several biases in the design of future solutions. By contrast, understanding perceived well-being drivers in urban parks of low- and middle-income countries presents an opportunity to create future regionally based research platforms focused on different urbanization processes. Here, we address the relationship between ecological knowledge and self-reported well-being in a middle-income country megacity as a baseline through which insights on this issue can be drawn.

We explored the relationship between ecological knowledge and self-reported well-being in a highly concurred urban park in downtown Santiago, Chile. We assessed the main perceptions about nature and green areas, as well as the preference of visitors. Then, we measured the ability to recognize and name different plant and bird species present in the park. Finally, we measured the self-reported well-being of visitors and explored how it related to their ecological knowledge. We hypothesized that knowledge is positively related to self-reported well-being, and this relationship might be reflected in people's notions and preferences. We predicted that ecological knowledge is lost, particularly for the native biota. We also predicted that a higher level of self-reported well-being relates to greater ability to recognize species.

\section{Materials and Methods}

\subsection{Research Setting}

Over $87 \%$ of the Chilean population inhabits urban areas [30], and 7,112,808 people $(40.47 \%$ of the country's population) live in the Metropolitan area of Santiago, the capital of Chile. This is considered as a megacity, as it holds a population density of 8495 habitants per $\mathrm{km}^{2}$. Santiago is placed within the Central Chile Biodiversity Hotspot [31]. However, even though the urban area has developed towards the most biodiverse Mediterranean zone of Chile, urban parks are not remnants from natural areas since they were built in the last century during the centenary celebrations, using exotic flora 
from Europe and Asia [32,33]. The urban zone possesses a total of 3825 ha of green areas, but only $3 \%$ $(n=358)$ have a size of 1 ha or more [34]. Although there is no consensus, the WHO uses an indicator of accessibility defined as the "percentage of citizens living within $300 \mathrm{~m}$ from a public open area of minimum size 0.5 hectares" [35]. In the case of Santiago, only $19.6 \%$ of inhabitants with low-level incomes meet this criterion, in contrast with the $74.1 \%$ of the wealthier population [34]. Additionally, the average of urban green areas is $3.2 \mathrm{~m}^{2}$ per capita, but this value also varies with income, showing between $0.9-2.9 \mathrm{~m}^{2} /$ habitant in the low-income areas and $6.7-18.8 \mathrm{~m}^{2} /$ habitant in the wealthier areas of the city [36]. Therefore, urban green areas are not evenly distributed across the city, and there is a high socioeconomic segregation in the accessibility and the size of green areas in Santiago [34].

\subsection{Study Site}

Research was performed in one of the most cosmopolitan and visited parks of downtown Santiago city, Parque Forestal $\left(33^{\circ} 26^{\prime} \mathrm{S} 70^{\circ} 38^{\prime} \mathrm{W}\right)$. It is $17 \mathrm{ha}$ in size and was officially inaugurated in 1905 . Its flora is dominated by conspicuous exotic species like oriental plane (Platanus orientalis) and cherry plum (Prunus cerasifera), along with some native species such as Acacia caven, Maytenus boaria, and Cryptocarya alba. Regarding the avian fauna, some common native species are the Austral Thrush (Turdus falcklandii) and the House Wren (Troglodytes musculus), which nest in this park, in addition to the exotics, Rock Dove (Columba livia) and the House Sparrow (Passer domesticus). Because of its extension and accessibility, Parque Forestal is considered one of the most important public green areas of the city.

\subsection{Sampling}

A total of 222 park users were surveyed between March 2016 and April 2017, during weekends. Two previously trained surveyors (including the first author) roamed across the park between 3 p.m. and 7 p.m., and chose people who were sitting or lying on the grass, using public infrastructure such as benches, trails, etc., or talking in groups. We did not ask people who were passing by or working, to prevent obtaining biased data from non-park users. An average response rate of $75 \%$ was achieved. The distribution of the sample included Chileans $(n=216,97.29 \%)$, aged a median of 23 years (range $18-83)$, women $(n=112,50.45 \%)$, and who had a higher educational level $(n=113,50.9 \%)$.

\subsection{Survey and Statistical Analysis}

To survey the park users, we designed a three-item semi-structured questionnaire, including free elicitation of word association, short-answered questions, Likert Scale and closed-ended questions. The instrument was piloted on 25 volunteers to adjust questions and timing, to make sure that the survey was correctly designed and applied. The survey had sections on perceptions, knowledge, well-being and some basic socioeconomic variables (see Supplementary Material S1).

To evaluate users' unbiased ideas and notions about nature, we first asked them to mention the first three concepts or words they related to parks [37]. These words were categorized a posteriori in five major areas: Nature, as every idea related to environment; Attachment, as the sense of belonging and emotion; Reflection, as the capacity of meditate or think; Equipment, as every resource or implement of a park; and others for every idea that could not be classified into these groups. Some of these areas were subdivided when possible into different categories. Results were presented as a word cloud to highlight the most repeated concepts using the package "wordcloud2" from R v4.0.0 software [38] on RStudio v1.2.5042 [39].

We assessed formal ecological knowledge based on Pilgrim et al. [25] and Celis-Diez et al. [24], considering it as the ability to recognize or name different urban plants $(n=10)$ and birds $(n=10)$ present in our studied urban park. For each taxon, we included native and exotic species commonly found in urban environments in Central Chile. For plants, we used pictures of 5 native and 5 exotic species; for birds, we used pictures of 7 native and 3 exotic species. We followed the method performed by Celis-Diez et al. [24]. We asked users to look at photos of different species for a maximum time of $1 \mathrm{~min}$ and name them. To facilitate the recognition of plants, we included images of the tree, its leaves, 
flowers, and fruits. Every answer was recorded as "correct" or "incorrect" (which included wrong answers and omissions), so every respondent had a total number of correct answers, and a ratio of native/exotic species recognized. Additionally, we asked respondents if they would like to see each species on a hypothetical park.

To assess users' preferences, we presented five attributes from a park and asked them to rank them, giving the first position to the most important element and the fifth place to the least relevant. The features were "bird abundance and diversity," "tree abundance and diversity," "infrastructure," "illumination and security," and "recreation infrastructure."

To assess users' well-being, we used the Feel Good Factor approach of Dallimer et al. [11], in which three main dimensions are described: (i) attachment, (ii) reflection, and (iii) continuity with past. We built a 7-statement matrix, adapted from Dallimer et al. [11], and asked respondents to recognize the degree of agreement with each one. We used the scale proposed by Marin et al. [40] in which respondents score in a 20-point continuous scale their agreement or disagreement with different statements. We calculated the overall Feel Good Factor as the average of the score values obtained for the three dimensions enquired.

To explore the relationship between ecological knowledge variables and users' well-being, we ran a quantile regression to analyze the effects at the extremes of the distribution of answers instead of the means. We chose to use quantile regression, because it allows for the estimation of the minimum well-being achieved as a function of ecological knowledge. We analyzed whether self-reported well-being was related to knowledge of birds and trees separately, with special focus on the knowledge of native species. All analysis was performed using the R v4.0.0 software [38] on RStudio v1.2.5042 [39].

\section{Results}

\subsection{Word Associations}

Citizens associated urban parks mainly with Nature (Figure 1). This was the most frequently named category with $48.05 \%$ ( $n=320$ out of 666 mentions). The second category was Attachment, with $37.99 \%(n=253)$, followed by Equipment $(12.16 \%, n=81)$ and Reflection $(4,0.006 \%)$. Specifically, the three most repeated concepts were "trees" $(n=100,15.02 \%)$, "grass" $(n=55,8.26 \%)$, and "nature" $(n=49,7.36 \%)$, and together represent the $30.63 \%(n=204)$ of the total mentions. Interestingly, only $1.77 \%$ mentions related to birds $(n=11)$. Other ecosystem features represented only $6 \%(n=40)$ of the total mentions, including concepts such as "air," "clouds," "water," and "soil."

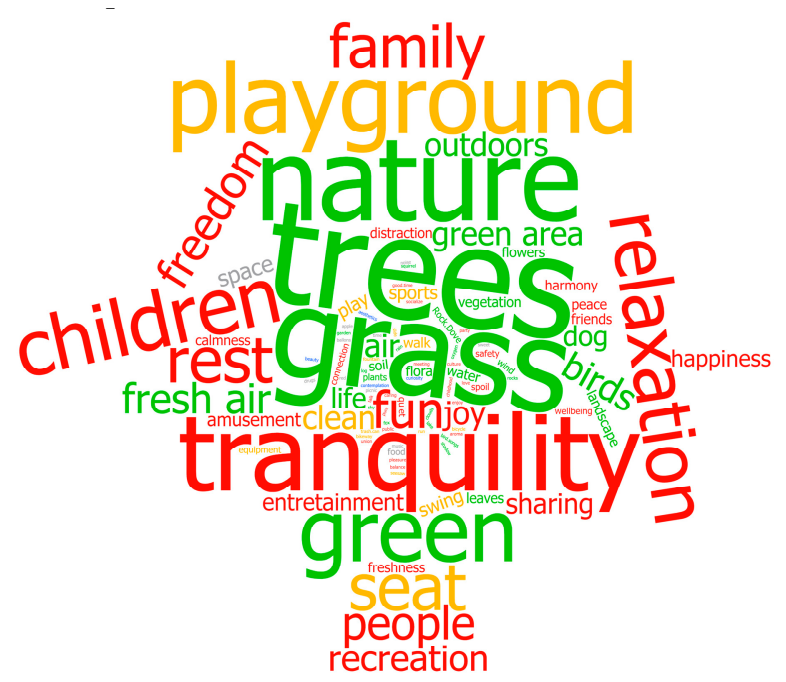

Figure 1. Word cloud containing the concepts mentioned by the participants. Sizes represent the frequency of mentions. Each word is also colored according to the respective category as follows: Nature (green), Attachment (red), Reflection (blue), Equipment (orange), and Others (grey). 


\subsection{Park Attributes and Preferences}

Users were asked to identify and rank 5 attributes of a park by sorting them from the most to the least important. They tended to place trees as the first preference (Figure 2). Meanwhile, "tree abundance and diversity" was given first preference on $54.50 \%$ of the cases, and only 5 people $(2.25 \%)$ assigned it to the least important place. Interestingly, "bird abundance and diversity" was considered on first preference only by $8(3.60 \%)$ users and assigned to the fifth place by $37.84 \%$ of them, being the most frequent attribute ranked in the last place (Figure 2). These results show a generalized valuation of trees as relevant elements of urban parks, followed by diverse implements and infrastructure.

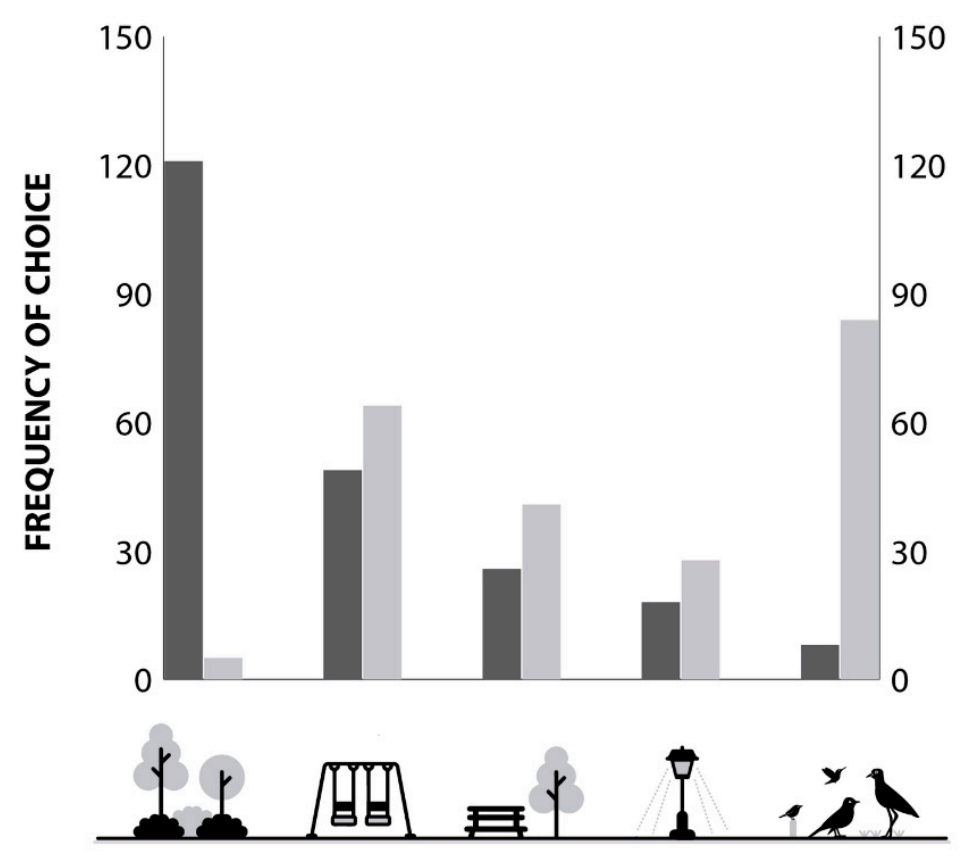

First choice

Last choice

Figure 2. Park attributes preference ranking. Here, we show preference distribution for each of the five elements presented to users, in order from left to right: "tree abundance and diversity," "recreation infrastructure," "infrastructure," "illumination and security," and "bird abundance and diversity." Dark grey bars represent the number of times each attribute was ranked in first position (most important); meanwhile, light grey bars represent the last ranking position (least important).

\subsection{Ecological Knowledge}

Regarding both trees and birds, respondents tended to recognize more exotic species (Figure 3). Native plants had an identification level of 0.65 correct answers (13.0\%) out of 5, while exotic species reached 1.38 correct answers $(27.60 \%)$ out of 5 . For birds, native species had an identification level of $1.08(15.40 \%)$ out of 7 , and the exotic species had $1.43(47.67 \%)$ out of 3 . These results show a generalized lack of knowledge of the native species in relation to the exotic ones (Figure 3). 

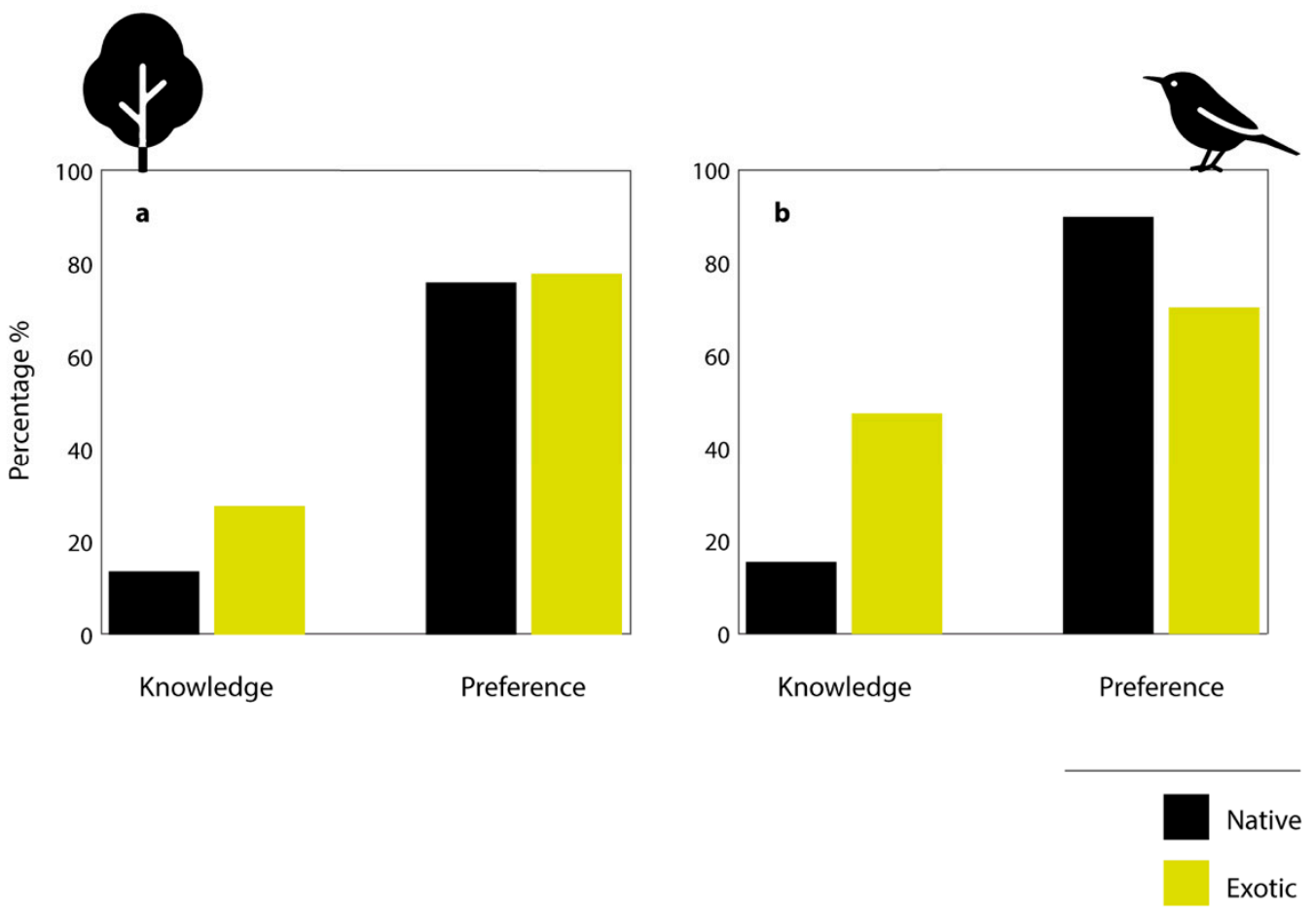

Figure 3. Ecological knowledge as percentage of correct identification and preference for trees (a) and birds (b) species. Native species are in black bars and exotic species are in yellow bars.

Urban park users gave a low number of correct responses to questions regarding the identification of species, with an average of 2.01 correct answers for plants and 2.44 for birds, out of a total of 10 questions. Additionally, 43 participants $(19.37 \%)$ were not able to identify any of the tree species presented. On the other hand, only 2 people $(0.90 \%)$ correctly identified 9 species of plants and 1 $(0.45 \%)$ could identify 9 species of birds. No respondent was able to identify all the species in both taxa (see Appendix A, Figure A1).

Regarding the flora, the cherry plum (Prunus cerasifera), an exotic species, was the most well-known plant, identified by 143 people (64.41\%). It was followed by a native tree, the roman cassie (Acacia caven), with $100(45.05 \%)$, and the exotic and invasive silver wattle (Acacia dealbata), with $73(32.88 \%)$ correct answers. The rest of the species did not surpass $30 \%$ of correct identification (see Appendix A, Figure A1). The less well-known species was the native Mayten tree (Maytenus boaria), correctly identified only by $4(1.8 \%)$ people (see Appendix A, Figure A1).

In the case of birds, the Rock Dove (Columba livia), an exotic species, was the only bird correctly identified by every surveyed person. It was followed by two native species: the Eared Dove (Zenaida auriculata), correctly identified by 85 respondents (38.29\%), and the Austral Thrush (Turdus falcklandii), correctly identified by 64 respondents $(28.83 \%)$. The less well-known species was the native Tufted Tit-tyrant (Anairetes parulus), identified only by 4 people (1.8\%) (see Appendix A, Figure A1).

With respect to user's preferences, a great proportion of surveyed people responded positively for most of the species of trees and birds, either native or exotic. When we analyzed preferences by origin, plants had an average preference of $79.87 \%$ and $82.1 \%$ for native and exotic species, respectively (Figure 3a). The most preferred species was Peruvian pepper (Schinus molle), with $94.14 \%$ of positive answers, and the least one was the Roman cassie (Acacia caven), with $50.45 \%$, both native species (see Appendix A, Figure A1).

On the other hand, respondents preferred native birds over exotic ones (Figure $3 b$ ). An average preference of $89.89 \%$ and $70.42 \%$ for native and exotic species was reported, respectively (Figure $3 b$ ). The two most preferred species were the Austral Thrush (Turdus falcklandii) and the rufous-collared 
Sparrow (Zonotrichia capensis), both native, and presented $95.05 \%$ of positive answers. The least one was the Rock Dove (Columba livia), with only $37.84 \%$ of positive answers (see Appendix A, Figure A1).

\subsection{Exploring the Relationship between Knowledge and Well-Being}

When we measured self-reported well-being, respondents showed an average score mean (SD) of 15.974 (3.690) out of 20 points for "Reflection," 16.959 (3.637) for "Attachment," and 15.315 (3.649) for "Continuity with past." The mean value for our sample was 16.083 (2.794) points. This value corresponded to the percentile 0.776 of a distribution of values between 0 and 20 points.

We explored how ecological knowledge related to self-reported well-being. When plotting the values of ecological knowledge of trees (Figure 4a) and birds (Figure $4 b$ ), we found that the variance of self-reported well-being tended to be greater when people showed low ecological knowledge scores and diminished as the knowledge score increased. This scatter pattern showed a marked exclusion zone, where no observations were found. The lower limit of this area represents the minimum value of well-being reported for each score of ecological knowledge. This resulted in a positive relation between ecological knowledge and well-being that was suited to be described by quantile regression analyses. This pattern was consistent between both tree and bird knowledge (Figure $4 \mathrm{a}, \mathrm{b}$ ).
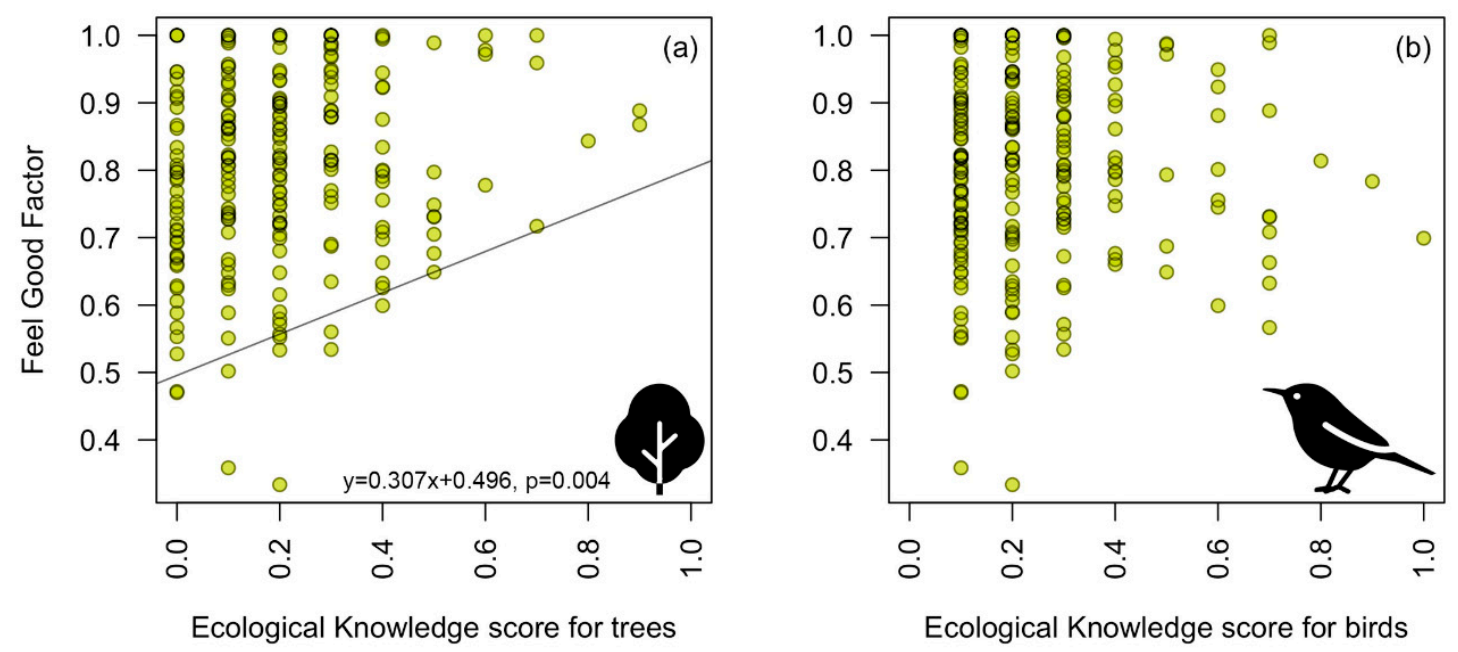

Figure 4. Self-reported well-being (Feel good factor) by Ecological Knowledge. (a) Tree Ecological Knowledge. Curve represents a quantile regression (tau $=0.05, p=0.004$ ). (b) Bird Ecological Knowledge. No significant relation was found (tau $=0.05, p=0.125)$.

We found a significant relationship between ecological knowledge of trees (without a distinction of its origin) and self-reported well-being $\left(n=222, \mathrm{~F}_{1443}=8.344, p=0.004\right)$ for the lower quantile $(\operatorname{tau}=0.05)$ of the distribution (Figure $4 a)$. However, this pattern was not significant for bird ecological knowledge $\left(n=222, \mathrm{~F}_{1443}=2.365, p=0.125\right)$ (Figure $\left.4 \mathrm{~b}\right)$. We also found no significant relationship between the self-reported well-being and ecological knowledge of native trees $\left(n=222, \mathrm{~F}_{1443}=0.103\right.$, $p=0.748)$ and native birds $\left(n=222, \mathrm{~F}_{1443}=1.094, p=0.296\right)$ related to self-reported well-being (All datasets are available in the Figshare repository https://doi.org/10.6084/m9.figshare.12609941.v1).

\section{Discussion}

This study showed that people consistently associated urban parks with nature. It was the most frequently named category in the survey with $40 \%$ of all the concepts. Specifically, the words "nature," "trees and vegetation," and "green" were the most named concepts, placing plants as the main association interviewees have with the word "park." This result matches with the valuation of trees as the most important feature of the park when ranked against the other five attributes. On the 
other hand, there were only a few mentions related to birds $(n=11,1.65 \%)$. This is consistent with the fact that "abundance and diversity of birds" was consistently ranked as the least important attribute.

Trees have been shown to contribute disproportionately towards nature experiences in socioeconomically deprived neighbors with high-density housing, such as many urban neighborhoods in Latin America. Some studies have shown that trees are highly valued because of their provision of shading and cooler surroundings [41], as well as the positive effects on people's mental health [14]. Thus, it is likely that people tend to be more aware of the immediate ecosystem services provided by plants. In fact, some concepts such as "air purification" and "shadow availability" were mentioned during the survey. As people become more conscious of these benefits, it is more likely for them to recognize the importance of vegetation.

While respondents associated urban parks with nature, when we evaluated people's ability to recognize and name plant and bird species, we found low scores for both taxa. This lack of ecological knowledge is consistent not only with the pattern found in recent studies in other parks of Santiago [24], but also with what other authors have found in other cities across the world [12,13,23,26]. However, drivers of ecological knowledge loss may differ between high- and low-income countries. Pilgrim et al. [25] compared ecological knowledge between high- and low-income countries and showed that UK respondents presented lower scores for ecological knowledge than respondents from developing countries. On the other hand, and contrary to what Pilgrim [25] pointed out, in Latin American countries, where there is high socioeconomic segregation in the distribution of green areas [34], Bermúdez [22] found that wealthier sectors in Argentina were able to recognize a greater number of species compared to low-income sectors. Perelman et al. [42] also suggested a positive relation between educational level and ability to recognize species. These apparently contradictory results could be a result of the importance of direct contact with nature on the acquisition of ecological knowledge [14,24]. Latin American megacities show high socioeconomic segregation, with wealthier sectors having increased opportunities to experience nature [34]. Therefore, ecological knowledge loss in developing countries is probably a combination between urbanization processes and a restriction of direct nature experiences, mediated by socioeconomic factors. Chile, despite having a high GDP-per-capita (25,222.5 USD for 2018) in contrast to other Latin American countries, has high inequality in income distribution (Gini coefficient $2018=45.90 \%$ ), with $80 \%$ of the population receiving salaries under 1000 USD [43].

Identification rates were low for both native and exotic species (for both plants and birds), but exotic species were more likely to be identified. One possible explanation relates to the underrepresentation of native species within the green infrastructure of Santiago city. For example, Rozzi et al. [32] found that nearly $95 \%$ of trees present in urban parks of eight major cities of Chile were exotic species, which contrasts with $40 \%$ of the flora of central European cities [44]. Exotic species are more prevalent in populated areas of the city (see Rozzi et al. [32] and Celis-Diez et al. [24] for trees and birds, respectively); thus, people are exposed to them more often. Also, in the case of birds, common urban species, such as the exotic ones in Santiago, tend to have less fear of humans so they can be more easily spotted [45]. Therefore, it is more likely for exotic species to be part of the collective imaginaries. This is a symptom of the "Shifting baseline syndrome" [15], a progressive change in how people conceive the natural environment and its condition, due to lack of past information or lack of experience of past states. Thus, as urban people have been more exposed to exotic biota, they are more prone to consider them as originally to that place [26].

Despite the lack of formal biological knowledge about the species, interviewees showed on average high levels of self-reported well-being (over percentile 70) and a great variability in those scores. This variability increased as the scores of ecological knowledge dropped (Figure 4). This pattern was consistent for both trees and birds. However, when running a quantile regression, we found that the relationship was only statistically significant for ecological knowledge of trees $\left(n=222, \mathrm{~F}_{1443}=8.344\right.$, $p=0.004)$. This suggests that increasing levels of ecological knowledge of trees are related to higher and less variable scores of self-reported well-being, but there is no significant relation with bird 
knowledge or knowledge by species origin. However, our study was limited by the visual recognition of taxa, and it is important to consider that other sensory stimuli, such as audition [46], are relevant to understand the links between biodiversity, knowledge, and well-being.

In our results, as in those of Muratet et al. [47], urban dwellers tend to value plants due to aesthetic criteria, but biodiversity and ecological functions are rarely considered. This can be explained by the generalized lack of knowledge of plants in the first place. If people cannot correctly identify trees and plants in general, it is less likely that they are aware of the characteristic features and ecological role of each species; hence, the difference between native and exotic species is meaningless. In Poland, Suchocka et al. [48] found that the overall perception of trees tended to be positive, and the benefits of green infrastructure can mask any possible harm caused by them, and according to this, Shanahan et al. [49] found that Australian people with a greater orientation towards nature tend to travel further to visit more vegetated parks.

Results suggest that interviewees perceive trees as a homogenous attribute. Wandersee and Schussler [50] named this phenomenon as "plant blindness," as people tend to overlook plants and perceive them as a bulk rather than single organisms. However, these authors proposed that education is a key factor that enhances the acknowledgment of trees and the ecosystem services they provide, for example, a suitable habitat for other native taxa. This can also be useful in urban environments, where knowledge can help mitigate conflicts related to urban green infrastructure. However, future research should aim to discriminate preferences between different vegetative life forms (i.e., grasslands, shrubs, or trees), as recent studies have shown that spatial heterogeneity of urban green areas may be related to psychological response [20]. Therefore, assessing this relationship is crucial to better understand the case of Chile, since most of the urban parks of the metropolitan area are of the "Savanna type": a simple structure with grass and isolated trees.

The relationship between well-being and biodiversity is not equal between taxa. For instance, a study conducted in Australia showed that personal well-being related to a Normalized Difference Vegetation Index (NDVI) but not to bird species richness [51]. However, other authors have shown a positive relationship between birds and well-being [12]. In our study, bird knowledge did not relate to self-reported well-being. However, unlike some developed countries (e.g., the United Kingdom, New Zealand, and North America), where there is a widespread traditional culture of wildlife appreciation, such as gardening, bird watching, the behavior of feeding birds, and other "wildlife friendly" gardening practices [52,53], these practices are uncommon in Chile. The Rock Dove (Columba livia) was recognized by every participant. Given that this is a (i) synanthropic exotic species, (ii) extremely conspicuous in urban habitats, (iii) vector of zoonotic diseases such as Salmonella [54], and (iv) often associated with dumpsters and dirty areas, the association is likely to impact the notion of birds in general, in a similar way as the 'plant blindness' phenomenon occurs. Even when people may perceive songbirds separately from non-songbirds, or when some species, such as Columba livia, disproportionately increase in abundance, this could provide a cultural disservice to urban residents [45], which may also extrapolate this perception to all birds. This phenomenon was described by Belaire et al. [55], as people's valuation was linked to perceived bird richness rather than actual richness, which in turn is biased towards the most conspicuous species [56]. This perception only included a few common urban species that presented several negative qualities that may have influenced the overall perception of birds. This result suggests again the critical role of knowledge as a mediator of the relationship between humans and nature.

More research is needed to understand the mechanisms underpinning the relationship between knowledge and well-being. Knowledge allows us to make better decisions that acknowledge the relevance of green areas as a key component of urban residents' well-being in cities. However, knowledge can also reshape perceptions and attitudes towards the environment, letting people acknowledge the value of urban green areas and possibly helping to restore gaps between humans and nature. In fact, people who perceive biodiversity more accurately are more likely to present higher well-being rates [56]. Lumber et al. [57] highlighted the role of emotion, compassion, and beauty 
of being in nature as critical pathways for well-being, extending the consideration of only cognitive dimensions of well-being. Hence, we can expect that the extinction of the experience produced by living in cities could be reduced by providing places to experience nature and platforms where civil society can engage with and develop ecological knowledge. This engagement provides opportunities to also enhance traditional knowledge and other forms of local ecological knowledge [58], thus extending the knowledge base beyond the "names" of different components of the ecosystem, and towards ecosystem functions, management, and ethics related to them. Interestingly, in an urban context, Harvey et al. [59] described ten different things that children notice in nature, suggesting that they should be considered when designing programs to stimulate awareness and connection with nature. Thus, it is crucial to incorporate biodiversity and ecosystem function in policy making and planning to improve people's well-being in urban areas [60]. It is also relevant to enhance direct contact with nature and everyday perceptions of biodiversity [61], through the development of specific programs, campaigns, and community-based learning communities within megacities.

Our study has limitations, such as the bias in the ages of the respondents, sampling on weekends and a focus on cognitive dimensions. Additionally, more diversity in socioeconomic aspects of urban dwellers and other dimension could be assessed in further studies. However, we believe that our study provides basic elements to initiate further work on perceived well-being in Latin American contexts where segregation represents a critical issue.

In conclusion, this study explored the state of and the relationship between ecological knowledge of trees and birds and self-reported well-being in Santiago, a megacity of a middle-income country. Results suggest that although ecological knowledge is relatively low, knowledge of trees is positively related with self-reported well-being. The lack of ecological knowledge is a phenomenon reported for several high- and low-income countries. However, drivers may be different, as cities have been formed at a different scale and pace. Latin American countries as well as other developing regions have presented dramatic urbanization rates in the last decades. Therefore, understanding the drivers of ecological knowledge loss in low- and middle-income countries is crucial. Future research must assess this issue in order to mitigate the effects of urban sprawl in high biodiversity areas and promote local-based strategies for biological and cultural conservation.

Supplementary Materials: The following are available online at http://www.mdpi.com/2071-1050/12/18/7586/s1, Supplementary Material S1: Survey and informed consent translated into English and in the original language (Spanish).

Author Contributions: Conceptualization, A.P.-S., J.L.C.-D., and S.G.; methodology A.P.-S., J.L.C.-D., and S.G.; data acquisition, A.P.-S.; formal analysis, A.P.-S., S.A., and J.L.C.-D.; writing-review and editing, A.P.-S., J.L.C.-D., S.A., and S.G.; funding acquisition, J.L.C.-D. and S.G. All authors have read and agreed to the published version of the manuscript.

Funding: This research was funded by the Agencia Nacional de Investigación y Desarrollo ANID, Chile (https://www.anid.cl) through grants FONDECYT 3130672 to J.L.C.-D., ANID PIA/BASAL/FB0002 to S.G., Núcleo Milenio MUSELS (NC120086) to S.G., FONDECYT 1170995 to S.A., and ANID/PIA/ACT192027 to J.L.C.-D. and S.A.

Acknowledgments: We acknowledge DTC Cox for valuable comments on an early version that helped to improve this manuscript and S. Lazzarino for helping with the design of the figures. J.L.C.-D. is an adjunct researcher at the Instituto de Ecología y Biodiversidad (IEB).

Conflicts of Interest: The authors declare no conflict of interest. The funders had no role in the design of the study; in the collection, analyses, or interpretation of data; in the writing of the manuscript, or in the decision to publish the results. 


\section{Appendix A}

(a)

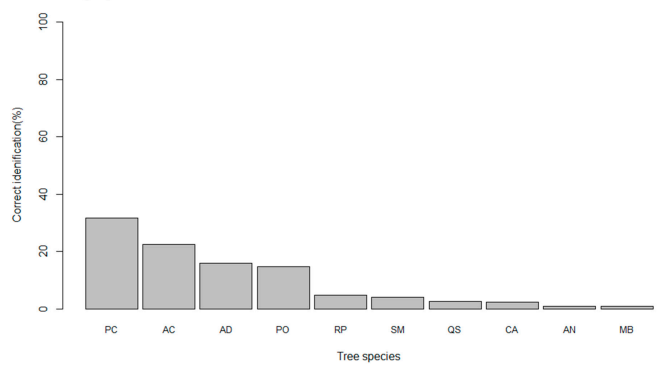

(c)

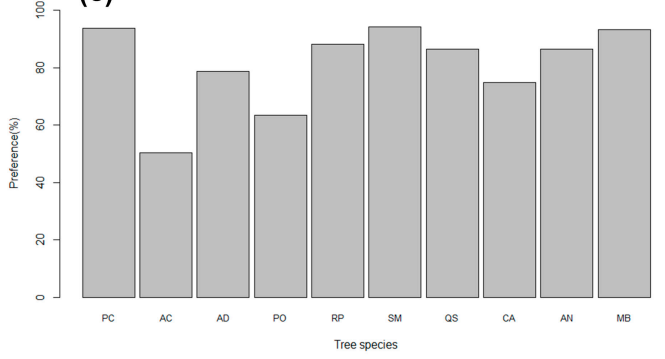

(b)

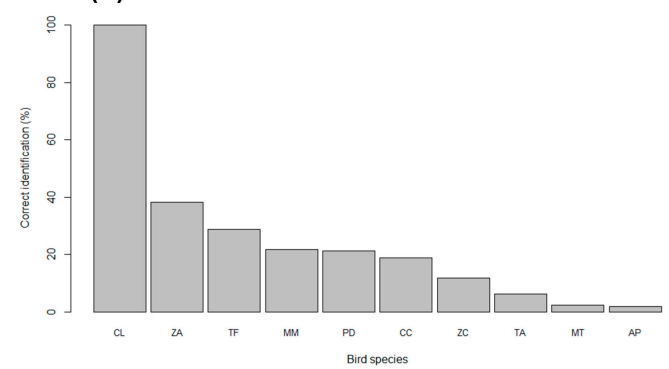

(d)

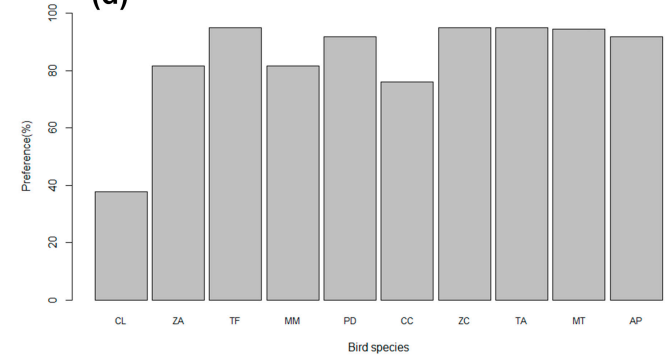

Figure A1. Ecological knowledge (a,b), as correct identification percentage, for trees (a) and birds (b) species, and preference (c,d) for trees (c) and birds (d) species. Tree species abbreviation and its origin within parenthesis were: PC Prunus cerasifera (exotic); AC Acacia caven (native); AD Acacia dealbata (exotic); PO Platanus orientalis (exotic); RP Robinia pseudoacacia (exotic); SM Schinus molle (native); QS Quillaja saponaria (native); CA Cryptocarya alba (native); AN Acer negundo (exotic); MB Maytenus boaria (native). Bird species abbreviation and its origin within parenthesis were: CL Columba livia (exotic); ZA Zenaida auriculata (native); TF Turdus falcklandii (native); MM Myiopsitta monachus (exotic); PD Passer domesticus (exotic); CC Curaeus curaeus (native); ZC Zonotrichia capensis (native); TA Troglodytes aedon (native); MT Mimus thenca (native); AP Anairetes parulus (native).

\section{References}

1. Martin, L.J.; Blossey, B.; Ellis, E. Mapping where ecologists work: Biases in the global distribution of terrestrial ecological observations. Front Ecol. Environ. 2012, 10, 195-201. [CrossRef]

2. Grimm, N.B.; Faeth, S.H.; Golubiewski, N.E.; Redman, C.L.; Wu, J.; Bai, X.; Briggs, J.M. Global change and the ecology of cities. Science 2008, 319, 756-760. [CrossRef] [PubMed]

3. Grimm, N.B.; Foster, D.; Groffman, P.; Grove, J.M.; Hopkinson, C.S.; Nadelhoffer, K.J.; Pataki, D.; Peters, D.P. The changing landscape: Ecosystem responses to urbanization and pollution across climatic and societal gradients. Front. Ecol. Environ. 2008, 6, 264-272. [CrossRef]

4. Alberti, M. The effects of urban patterns on ecosystem function. Int. Reg. Sci. Rev. 2005, 28, 168-192. [CrossRef]

5. McKinney, M.L. Effects of urbanization on species richness: A review of plants and animals. Urban Ecosyst. 2008, 11, 161-176. [CrossRef]

6. Kaye, J.P.; Groffman, P.M.; Grimm, N.B.; Baker, L.A.; Pouyat, R.V. A distinct urban biogeochemistry? Trends Ecol. Evol. 2006, 21, 192-199. [CrossRef]

7. Elmqvist, T.; Fragkias, M.; Goodness, J.; Güneralp, B.; Marcotullio, P.J.; McDonald, R.I.; Parnell, S.; Schewenius, M.; Sendstad, M.; Seto, K.C.; et al. Stewardship of the Biosphere in the Urban Era. In Urbanization, Biodiversity and Ecosystem Services: Challenges and Opportunities, 1st ed.; Elmqvist, T., Fragkias, M., Goodness, J., Güneralp, B., Marcotullio, P.J., McDonald, R.I., Parnell, S., Schewenius, M., Sendstad, M., Seto, K.C., et al., Eds.; Springer: Dordrecht, The Netherlands, 2013; pp. 719-746. [CrossRef] 
8. Cox, D.T.C.; Gaston, K.J. Human-nature interactions and the consequences and drivers of provisioning wildlife. Phil. Trans. R. Soc. B Biol. Sci. 2018, 373, 20170092. [CrossRef]

9. Shanahan, D.F.; Lin, B.B.; Gaston, K.J.; Bush, R.; Fuller, R.A. Socio-economic inequalities in access to nature on public and private lands: A case study from Brisbane, Australia. Landsc. Urban Plan. 2014, 130, 14-23. [CrossRef]

10. Soga, M.; Gaston, K.J. Extinction of experience: The loss of human-nature interactions. Front. Ecol. Environ. 2016, 14, 94-101. [CrossRef]

11. Dallimer, M.; Irvine, K.N.; Skinner, A.M.J.; Davies, Z.G.; Rouquette, J.R.; Maltby, L.L.; Warren, P.H.; Armsworth, P.R.; Gaston, K.J. Biodiversity and the Feel-Good Factor: Understanding Associations between Self-Reported Human Well-being and Species Richness. BioScience 2012, 62, 47-55. [CrossRef]

12. Fuller, R.A.; Irvine, K.N.; Devine-Wright, P.; Warren, P.H.; Gaston, K.J. Psychological benefits of greenspace increase with biodiversity. Biol. Lett. 2007, 3, 390-394. [CrossRef] [PubMed]

13. Russell, R.; Guerry, A.D.; Balvanera, P.; Gould, R.K.; Basurto, X.; Chan, K.M.A.; Klain, S.; Levine, J.; Tam, J. Humans and nature: How knowing and experiencing nature affect well-being. Annu. Rev. Environ. Resour. 2013, 38, 473-502. [CrossRef]

14. Cox, D.T.C.; Hudson, H.L.; Shanahan, D.F.; Fuller, R.A.; Gaston, K.J. The rarity of direct experiences of nature in an urban population. Landsc. Urban Plan. 2017, 160, 79-84. [CrossRef]

15. Soga, M.; Gaston, K.J. Shifting baseline syndrome: Causes, consequences, and implications. Front. Ecol. Environ. 2018, 16, 222-230. [CrossRef]

16. Soga, M.; Gaston, K.J.; Koyanagi, T.F.; Kurisu, K.; Hanaki, K. Urban residents' perceptions of neighbourhood nature: Does the extinction of experience matter? Biol. Conserv. 2016, 203, 143-150. [CrossRef]

17. Soga, M.; Gaston, K.J.; Yamaura, Y.; Kurisu, K.; Hanaki, K. Both direct and vicarious experiences of nature affect children's willingness to conserve biodiversity. Int. J. Environ. Res. Public Health 2016, 13, 529. [CrossRef]

18. Miller, J.R. Biodiversity conservation and the extinction of experience. Trends Ecol. Evol. 2005, 20, 430-434. [CrossRef]

19. Wilson, E.O. Biophilia; Harvard University: Cambridge, MA, USA, 1984.

20. Cameron, R.W.; Brindley, P.; Mears, M.; McEwan, K.; Ferguson, F.; Sheffield, D.; Jorgensen, A.; Riley, J.; Goodrick, J.; Ballard, L.; et al. Where the wild things are! Do urban green spaces with greater avian biodiversity promote more positive emotions in humans? Urban Ecosyst. 2020, 23, 301-317. [CrossRef]

21. Ballouard, J.M.; Brischoux, F.; Bonnet, X. Children prioritize virtual exotic biodiversity over local biodiversity. PLOS ONE 2011, 6, e23152. [CrossRef]

22. Bermúdez, G.; De Longhi, A. La educación ambiental y la ecología como ciencia. Revista Electrónica Enseñanza de las Ciencia 2008, 7, 275-297.

23. Campos, C.M.; Nates, J.; Lindemann-Matthies, P. Percepción y conocimiento de la biodiversidad por estudiantes urbanos y rurales de las tierras áridas del centro-oeste de Argentina. Ecol. Austral. 2013, 23, 174-183.

24. Celis-Diez, J.L.; Muñoz, C.E.; Abades, S.; Marquet, P.A.; Armesto, J.J. Biocultural homogenization in Urban settings: Public knowledge of birds in city parks of Santiago, Chile. Sustainability 2017, 9, 485. [CrossRef]

25. Pilgrim, S.E.; Cullen, L.C.; Smith, D.J.; Pretty, J. Ecological knowledge is lost in wealthier communities and countries. Environ. Sci. Technol. 2008, 42, 1004-1009. [CrossRef] [PubMed]

26. Robinson, B.S.; Inger, R.; Gaston, K.J. A rose by any other name: Plant identification knowledge \& socio-demographics. PLoS ONE 2016, 11, e0156572. [CrossRef]

27. Cox, D.T.C.; Gaston, K.J. Likeability of garden birds: Importance of species knowledge \& richness in connecting people to nature. PLoS ONE 2015, 10, e0141505. [CrossRef]

28. Rumble, H.; Angeoletto, F.; Connop, S.; Goddard, M.A.; Nash, C. Understanding and Applying Ecological Principles in Cities. In Planning Cities with Nature, 1st ed.; Lemes de Oliveira, F., Mell, I., Eds.; Springer: New York, NY, USA, 2019; pp. 217-234.

29. Kraas, F. Megacities and global change in East, Southeast and South Asia. Asien 2007, 103, 9-22.

30. Web Diseminación Censo. Available online: http://resultados.censo2017.cl/ (accessed on 20 July 2020).

31. Myers, N.; Mittermeier, R.; Mittermeier, C.; da Fonseca, G.; Kent, J. Biodiversity hotspots for conservation priorities. Nature 2000, 403, 853-858. [CrossRef] 
32. Rozzi, R.; Massardo, F.; Silander, J., Jr.; Dollenz, O.; Connolly, B.; Anderson, C.; Turner, N. Árboles nativos y exóticos en las plazas de Magallanes. Native and exotic tree species in the squares of the Magellan Region. An. Inst. Patagon. 2003, 31, 27-42.

33. Figueroa, J.A.; Castro, S.A.; Reyes, M.; Teillier, S. Urban park area and age determine the richness of native and exotic plants in parks of a Latin American city: Santiago as a case study. Urban Ecosyst. 2018, 21, 645-655. [CrossRef]

34. Reyes-Paeke, S.; Aldunce, I.M.F. Distribution, size and accessibility of green areas in Santiago de Chile. EURE 2010, 36, 89-110. [CrossRef]

35. Urban Green Spaces and Health: A Review of Evidence. Available online: https://www.euro.who.int/_data/ assets/pdf_file/0005/321971/Urban-green-spaces-and-health-review-evidence.pdf (accessed on 20 July 2020).

36. Plan Verde: Un Instrumento Para la Gestión y el Fomento de áreas Verdes en el Gran Santiago. Available online: http://redalyc.uaemex.mx/pdf/198/19800805.pdf (accessed on 20 July 2020).

37. Gelcich, S.; Cinner, J.; Donlan, C.; Tapia-Lewin, S.; Godoy, N.; Castilla, J.C. Fishers' perceptions on the Chilean coastal TURF system after two decades: Problems, benefits, and emerging needs. Bull. Mar. Sci. 2017, 93, 53-67. [CrossRef]

38. R Core Team. R: A Language and Environment for Statistical Computing; R Foundation for Statistical Computing: Vienna, Austria, 2020. Available online: https://www.R-project.org/ (accessed on 20 July 2020).

39. RStudio Team. RStudio: Integrated Development for R. RStudio; PBC: Boston, MA, USA, 2020. Available online: http://www.rstudio.com/ (accessed on 20 July 2020).

40. Marín, A.; Gelcich, S.; Castilla, J.C. Ecosystem services and abrupt transformations in a coastal wetland social-ecological system: Tubul-Raqui after the 2010 Earthquake in Chile. Ecol. Soc. 2014, 9, 1983. [CrossRef]

41. Lohr, V.I.; Pearson-Mims, C.H.; Tarnai, J.; Dillman, D.A. How urban residents rate tree benefits and problems. Arboric. J. 2002, 30, 28-35.

42. Perelman, P.; Breuste, J.; Madanes, N.; Gropper, C.; Melignani, E.; Faggi, A. Use of visitors' perception in urban reserves in the Buenos Aires metropolis. Urban Ecosyst. 2012, 16, 841-851. [CrossRef]

43. Durán, G.; Kremerman, M. Los bajos salarios de Chile. Análisis de la Encuesta CASEN 2015. Ideas Para el Buen Vivir 2017, 14, 1-8.

44. Pyšek, P. Alien and native species in Central European urban floras: A quantitative comparison. J. Biogeogr. 1998, 25, 155-163. [CrossRef]

45. Cox, D.T.C.; Hudson, H.L.; Plummer, K.E.; Siriwardena, G.M.; Anderson, K.; Hancock, S.; Devine-Wright, P.; Gaston, K.J. Covariation in urban birds providing cultural services or disservices and people. J. Appl. Ecol. 2018, 55, 2308-2319. [CrossRef]

46. Corney, H.; Neave, M. I can hear the birds: Using audio recordings to assess perceptions of amenity in urban riparian environments. Urban Ecosyst. 2019, 22, 235-247. [CrossRef]

47. Muratet, A.; Pellegrini, P.; Dufour, A.B.; Arrif, T.; Chiron, F. Perception and knowledge of plant diversity among urban park users. Landsc. Urban Plan. 2015, 137, 95-106. [CrossRef]

48. Suchocka, M.; Jankowski, P.; Błaszczyk, M. Perception of urban trees by polish tree professionals vs. nonprofessionals. Sustainability 2019, 11, 211. [CrossRef]

49. Shanahan, D.F.; Lin, B.B.; Gaston, K.J.; Bush, R.; Fuller, R.A. What is the role of trees and remnant vegetation in attracting people to urban parks? Landsc. Ecol. 2015, 30, 153-165. [CrossRef]

50. Wandersee, J.H.; Schussler, E.E. Toward a theory of plant blindness. Plant Sci. Bull 2001, 47, 2-9.

51. Taylor, L.; Hahs, A.K.; Hochuli, D.F. Wellbeing and urban living: Nurtured by nature. Urban Ecosyst. 2017, 21, 197-208. [CrossRef]

52. Fuller, R.A.; Warren, P.H.; Armsworth, P.R.; Barbosa, O.; Gaston, K.J. Garden bird feeding predicts the structure of urban avian assemblages. Divers. Distrib. 2008, 14, 131-137. [CrossRef]

53. Moss, S.A. Bird in the Bush. In A Social History of Bird Watching; Aurum Press Ltd.: London, UK, 2004.

54. Suphoronski, S.A.; de Freitas Raso, T.; Weinert, N.C.; Seki, M.C.; Carrasco, A.D.O.T. Occurrence of Salmonella sp. and Escherichia coli in free-living and captive wild birds from 2010-2013 in Guarapuava, Paraná, Brazil. Afr. J. Microbiol. Res. 2015, 9, 1778-1782. [CrossRef]

55. Belaire, J.A.; Westphal, L.M.; Whelan, C.J.; Minor, E.S. Urban residents' perceptions of birds in the neighborhood: Biodiversity, cultural ecosystem services, and disservices. Condor 2015, 117, 192-202. [CrossRef] 
56. Southon, G.E.; Jorgensen, A.; Dunnett, N.; Hoyle, H.; Evans, K.L. Perceived species-richness in urban green spaces: Cues, accuracy and well-being impacts. Landsc. Urban Plan. 2018, 172, 1-10. [CrossRef]

57. Lumber, R.; Richardson, M.; Sheffield, D. Beyond knowing nature: Contact, emotion, compassion, meaning, and beauty are pathways to nature connection. PLOS ONE 2017, 12, e0177186. [CrossRef]

58. Berkes, F.; Colding, J.; Folke, C. Rediscovery of Traditional Ecological Knowledge as Adaptive Management. Ecol. Appl. 2000, 10, 1251-1262. [CrossRef]

59. Harvey, C.; Hallam, J.; Richardson, M.; Wells, R. The good things children notice in nature: An extended framework for reconnecting children with nature. Urban For. Urban Green. 2020, 49, 126573. [CrossRef]

60. Taylor, L.; Hochuli, D.F. Creating better cities: How biodiversity and ecosystem functioning enhance urban residents' wellbeing. Urban Ecosyst. 2015, 18, 747-762. [CrossRef]

61. Patrick, P.; Tunnicliffe, S.D. What Plants and Animals Do Early Childhood and Primary Students' Name? Where Do They See Them? J. Sci. Educ. Technol. 2011, 20, 630-642. [CrossRef]

(C) 2020 by the authors. Licensee MDPI, Basel, Switzerland. This article is an open access article distributed under the terms and conditions of the Creative Commons Attribution (CC BY) license (http://creativecommons.org/licenses/by/4.0/). 